J.Lake Sci.(湖泊科学), 2016, 28(1): 132-140

DOI 10. 18307/2016. 0115

(C) 2016 by Journal of Lake Sciences

\title{
近百年来枝角类群落响应洱海营养水平、外来鱼类引入以及水生植 被变化的特征
}

\author{
卢慧斌, 陈光杰**,蔡燕风, 王教元, 陈小林, 段立曾,张虎才 \\ (云南师范大学旅游与地理科学学院高原湖泊生态与全球变化重点实验室, 昆明 650500)
}

\begin{abstract}
摘 要: 近几十年来, 以大型湖泊为代表的云南部分湖泊受人类活动的持续影响出现了生态环境的明显变化. 洱海作为 云南面积第 2 大淡水湖泊, 经历了多重环境压力 (富营养化、外来鱼类引人、水生植被退化等) 的影响. 在湖泊现代监测数 据面临时段较短、缺乏连续记录的背景下, 湖泊沉积物的连续记录可以提供湖泊生态环境变化的长期历史并可用于生态 响应模式的识别. 以目前处于富营养水平的洱海为研究对象, 应用湖泊沉积物记录进行多指标分析, 探讨多重环境压力影 响下洱海枝角类群落的长期变化特征以及影响因素, 并与已有研究成果和现代监测数据进行对比, 探讨了枝角类群落对 环境压力响应的空间差异性. 通过分析沉积物枝角类记录, 重建了近百年来洱海枝角类群落的变化历史, 结果表明过去 100 年来, 枝角类的生物量总体呈增加趋势, 尤其从 1990 年左右开始, 象鼻溞生物量显著增加, 物种相对组成出现明显变 化 (如 Bosmina longispina 被 B. longirostris 取代). 同时象鼻溞的生物量、壳长与触角长度在 1990s 初期有明显降低的趋势, 与同期外来鱼类 (如银鱼)引种成功的时间一致. 限制性聚类分析结果表明, 枝角类群落结构的变化有 3 个主要阶段: 1990s 以前, 底栖枝角类为群落的主要组成; 1990-2000 年左右, 浮游枝角类 (以象鼻溞为主) 在枝角类群落结构中的比例 迅速增加; 从 2000 年以后, 枝角类群落组成以浮游枝角类为主. 同时, 枝角类数据的主成分 (PCA) 分析显示, 仅有 PCA 主 轴 1 呈现显著的变化且解释了群落结构变化的 $61.64 \%$,进一步分析表明水生植被变化可能是驱动枝角类变化的主要环 境梯度, 如底栖枝角类生物量减少响应了湖泊水生植被的退化. 与已有研究对比表明, 浅水湖区沉积物记录的枝角类生物 量在 $1970 \mathrm{~s}$ 急剧增加与 1980s 急剧降低等现象并没有被深水区的沉积物记录所反映, 指示了洱海生态系统的变化模式存 在空间差异性. 同时象鼻溞个体大小的变化模式反映了外来鱼类引入导致的鱼类捕食压力的变化. 总之, 本文揭示了枝角 类群落结构与生物量的长期变化, 反映了洱海富营养化过程、水生植被的退化与外来鱼类引人的长期驱动影响, 因此对 洱海的生态管理与修复工作应考虑多个环境压力的影响并加强对湖泊生态系统的评价.
\end{abstract}

关键词: 古湖沼学;洱海; 枝角类;群落结构;富营养化

\section{Cladoceran community responses to eutrophication, fish introduction and macrophyte degradation over the past century in Lake Erhai}

LU Huibin, CHEN Guangjie ${ }^{* *}$, CAI Yanfeng, WANG Jiaoyuan, CHEN Xiaolin, DUAN Lizeng \& ZHANG Hucai

(Key Laboratory of Plateau Lake Ecology and Global Change, School of Tourism \& Geography, Yunnan Normal University, Kunming 650500, P.R.China)

\footnotetext{
Abstract: Obvious environment changes have occurred in some lakes of Yunnan Province due to intensifying human impacts over the past decades, especially in large lakes. Lake Erhai is the second largest lake in the Yunnan by surface area, which experienced the pressures of multiple environmental stressors (e.g. eutrophication, fish invasion and macrophyte degradation). The application of lake sediment records enables us to reconstruct the long-term changes of lake environment and ecosystem dynamics in situation of less monitoring data. Here multi-proxy analyses of lake sediments were conducted from a short sediment core in the south and shal-
}

* 国家自然科学基金项目 (U1133601,41171048)、教育部科学技术研究项目 (213034A)、云南省中青年学术技术带头 人培养计划项目 (2012HB012)、云南省创新团队项目 (2011C1) 和云南省高端人才项目 (2010CI111) 联合资助. 2014-12-26 收稿;2015-04-17 收修改稿.卢慧斌(1990 ), 男, 硕士;E-mail: luhuibin611@ 163.com.

** 通信作者; E-mail: guangjiechen@ gmail.com. 
low basin of Lake Erhai, which are currently eutrophic. We aimed to recognize the long-term variations and driving factors of cladoceran community, and to test for whether spatial heterogeneity exists in community responses through a comparison with monitoring data and previous results from the deep basin of Lake Erhai. Our results showed that cladoceran production showed an overall increasing trend in the past century, and since 1990s bosminid production increased significantly with a general trend of the oligotrophic taxon of Bosmina longispina replaced by B. longirostris. In addition, bosminid production and the body size (i.e. carapace and antennule length) displayed a decrease during early 1990s, were in good correspondence with the period when the population of the exotic noodlefish was well established. Based on the constrained cluster analysis, the historical changes of cladoceran community were characterized by three distinct phases: littoral cladocerans were dominant before the $1990 \mathrm{~s}$ and the relative abundance of pelagic cladocerans increased rapidly from the 1990s before the pelagic cladocerans became predominant during early 2000s. The principal component analysis showed that the environmental gradient associated with macrophyte coverage accounted for $61.64 \%$ of the total variance in the cladoceran community. Compared with previous studies, we observed that the increased production of cladocerans during the 1970s and an abrupt decrease during the 1980s recorded in shallow basin of Lake Erhai were not reflected in the core from the deep basin, indicating that spatial heterogeneity exists in ecosystem changes of Lake Erhai. We also found the obvious shift of bosminid body sizes in response to fish introduction. Overall, our results revealed the long-term changes of cladoceran production and community structure mainly as a consequence of lake eutrophication and macrophyte degradation, while fish introduction also played a role in structuring zooplankton community through changing predation pressure. Therefore the environmental stressors which could be identified through sedimentary records should be taken into account for sustainable management and ecological restoration of Lake Erhai through facilitating lake ecosystem assessment.

Keywords: Paleolimnology; Lake Erhai ; cladoceran; community structure; eutrophication

伴随人类活动的加剧和社会经济的持续发展, 云南典型湖泊的生态系统结构与功能近年来发生了较大 变化. 作为云南省面积第 2 大湖泊,洱海在过去几十年里, 经历了富营养化、水生植被退化、水位剧烈变化、外 来鱼类引人以及土著鱼类丧失等多重环境压力的影响 ${ }^{[1-2]}$. 不同的环境压力对湖泊生态系统产生了重要影 响, 而这些环境压力的长期生态效应又可以被湖泊沉积物记录下来 ${ }^{[3]}$. 枝角类处于湖泊食物网的中间位置, 对湖泊生态环境的变化十分敏感, 已成为评价湖泊生态环境变化的重要指标之一 ${ }^{[4]}$. 目前对洱海湖泊生态系 统中部分重要的水生生物指标 (如枝角类群落) 缺乏长期、连续的监测数据和较为系统的研究, 尤其是对多 重环境压力驱动枝角类群落结构变化的长期效应缺乏系统研究, 因此急需开展对洱海枝角类群落长期变化 的历史重建与影响因子识别. 古湖沼学的研究方法与技术手段可以为研究湖泊生态系统的长期变化提供重 要信息. 例如, 湖泊食物网的一些重要组成部分 (如硅质藻类、几丁质无脊椎动物) 可以较好地在湖泊沉积物 中保存,使得它们成为古湖沼学研究中的重要生物指标, 它们在沉积物中的生物量、群落等信息可以用来重 建湖泊生物群落变化的历史,并为评价不同环境压力的长期生态效应提供基础数据 ${ }^{[5]}$.

$\mathrm{Liu}$ 等在洱海中部 (约 $20 \mathrm{~m}$ 水深) 提取了一根大约 $35 \mathrm{~cm}$ 长的沉积物柱状样, 通过分析沉积物中的枝角 类群落, 识别了近百年来多重环境压力 (富营养化、水生植被退化以及外来鱼类引人等) 对枝角类群落的影 响 ${ }^{[6]}$. 但是洱海水下地形复杂, 且洱海北部、中部以及南部水深及营养状况、水生植被覆盖等差异显著.洱海 不同区域的枝角类群落对湖泊经历的多重环境压力类型与长期响应特征是否相同, 仍然知之甚少. 本文拟通 过利用古湖沼学的方法手段, 通过提取洱海南部沉积物中的多指标信息, 识别洱海近百年来枝角类群落变 化的主要特征, 探讨了多重环境压力对枝角类群落变化的影响, 并与已有研究进行对比, 揭示洱海枝角类群 落对多重环境压力响应的空间差异模式, 以期为今后湖泊的管理与修复工作提供参考信息与基础数据.

\section{1 材料与方法}

\section{1 样品采集}

洱海 $\left(25^{\circ} 36^{\prime} \sim 25^{\circ} 58^{\prime} \mathrm{N}, 100^{\circ} 06^{\prime} \sim 100^{\circ} 18^{\prime} \mathrm{E}\right)$ 位于云南省大理白族自治州中部, 跨大理市和洱源县. 长 $42.58 \mathrm{~km}$, 最大宽 $8.0 \mathrm{~km}$, 平均宽 $5.8 \mathrm{~km}$, 面积 $249.0 \mathrm{~km}^{2}$, 最大水深 $20.7 \mathrm{~m}$, 平均水深 $10.17 \mathrm{~m}$, 为断陷陷落

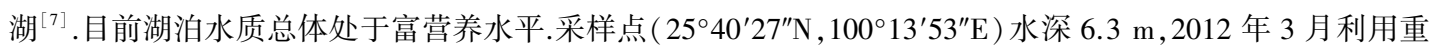
力采样器在该点采集柱状沉积样 (柱长 $45.4 \mathrm{~cm}$ ), 样品密封并避光保存后 $6 \mathrm{~h}$ 内在野外完成分样, 分样间隔 为 $0.5 \mathrm{~cm}$ (图 1). 


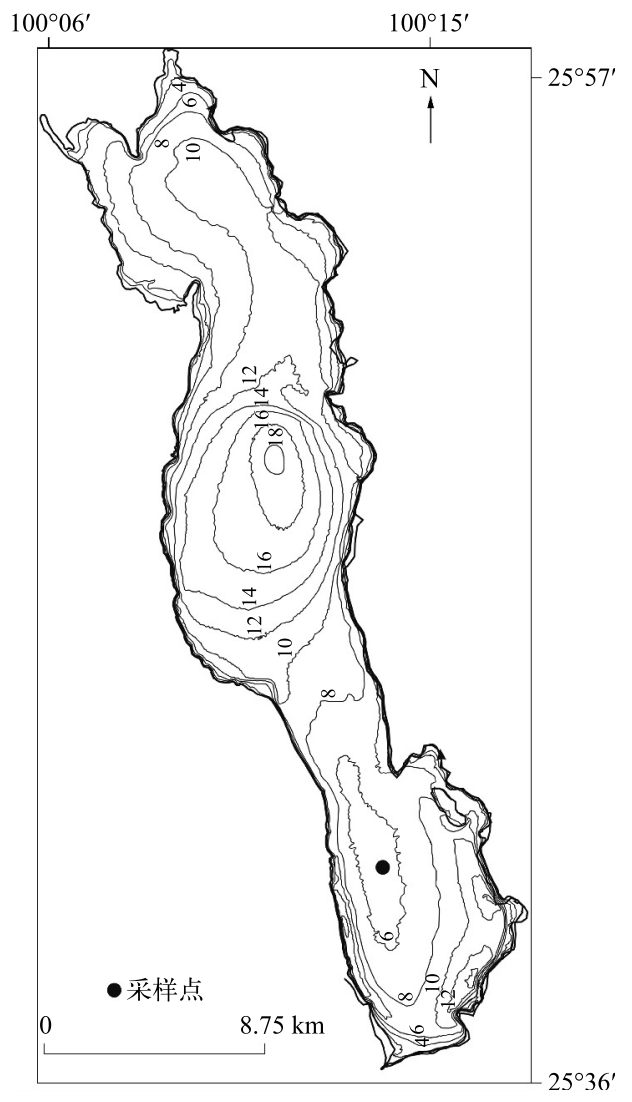

图 1 洱海采样点位置

Fig. 1 Location and coring site of Lake Erhai

\section{2 样品处理与数据分析}

通过对样品放射性核素 ${ }^{210} \mathrm{~Pb}$ 和 ${ }^{137} \mathrm{Cs}$ 进行测试分 析, 利用美国 Canberra 公司生产的高纯锗探测器、数字 化谱仪及多通道分析系统, 建立了钻孔的年代学序列. 具 体步骤包括: 将冻干的样品研磨, 称取 3 5 $\mathrm{g}$ (干重) 样品 放人与标准源同一规格的塑料容器内并蜡封 2 周左右, 使 ${ }^{226} \mathrm{Ra}$ 与 ${ }^{210} \mathrm{~Pb}$ 处于衰变平衡体系, 然后测定不同深度 样品的 ${ }^{210} \mathrm{~Pb}$ 和 ${ }^{137} \mathrm{Cs}$ 放射性强度, 并应用恒定放射性通 量模式建立年代学系列 (图 2) ${ }^{[8]}$.

沉积物枝角类样品的处理参照 Korhola 等的方法 ${ }^{[4]}$. 首先将冻干的样品充分混合均匀, 称取约 $0.1 \mathrm{~g}$ (干重) 样 品, 倒人 $100 \mathrm{ml}$ 烧杯中; 再加人 $50 \mathrm{ml}$ 的 $10 \% \mathrm{KOH}$ 溶液, 并在电热板上加热到 $70^{\circ} \mathrm{C}$ 左右约 $30 \mathrm{~min}$, 期间用玻璃棒 轻轻搅拌, 以使样品充分解絮凝; 然后用 $38 \mu \mathrm{m}$ 的篎网 过滤, 再用蒸馏水将篮网上的样品清洗到带有刻度的 $15 \mathrm{ml}$ 离心管中,加人 3 滴 95\% 的乙醇用于样品的室温 保存, 并定容. 再将样品充分摇匀, 利用 $0.05 \mathrm{ml}$ 的移液枪 吸取样品溶液, 置于载玻片上, 在电热板上以 $50^{\circ} \mathrm{C}$ 加热, 在样品蒸发待干前, 加人两滴甘油一藏红染料, 用针轻轻 搅拌使其混合并均匀分布, 将盖玻片置于其上, 待其冷 却后用指甲油密封盖玻片的边缘以便长期保存. 枝角类 的鉴定与计数在莱卡显微镜 (Leica DM2500) 下进行, 依 据 Frey ${ }^{[9-11]}$ 、Goulden 等 ${ }^{[12]}$ 的鉴定标准, 盘肠溞科的枝角 类鉴定到种的水平, 其中 Alona spp. 为 A. rectangula、A. guttata 与 A. costata 的合并, 基于象鼻溞的头孔将其分为 Bosmina longispina 与 B. longirostris 两个种, 溞科的枝角 类基于其尾爪分为 Daphnia longispina 与 D. pulex 两个群

组,Daphnia 为两个群组的合并. 同时统计头壳、壳畖、后腹部的个数以确定个体的数量, 每个样品中枝角类 的计数不少于 100 个,最后换算成通量 (每平方厘米每年沉积的枝角类个体数量) 作为生物量的指标. 并测 量玻片中所见象鼻溞的第一触角长度 $(A L)$ 、壳长 $(C L)$ 与刺长 $(M L)^{[13]}$, 每个样品中象鼻溞不同部位的测量 样本个数不低于 10 .
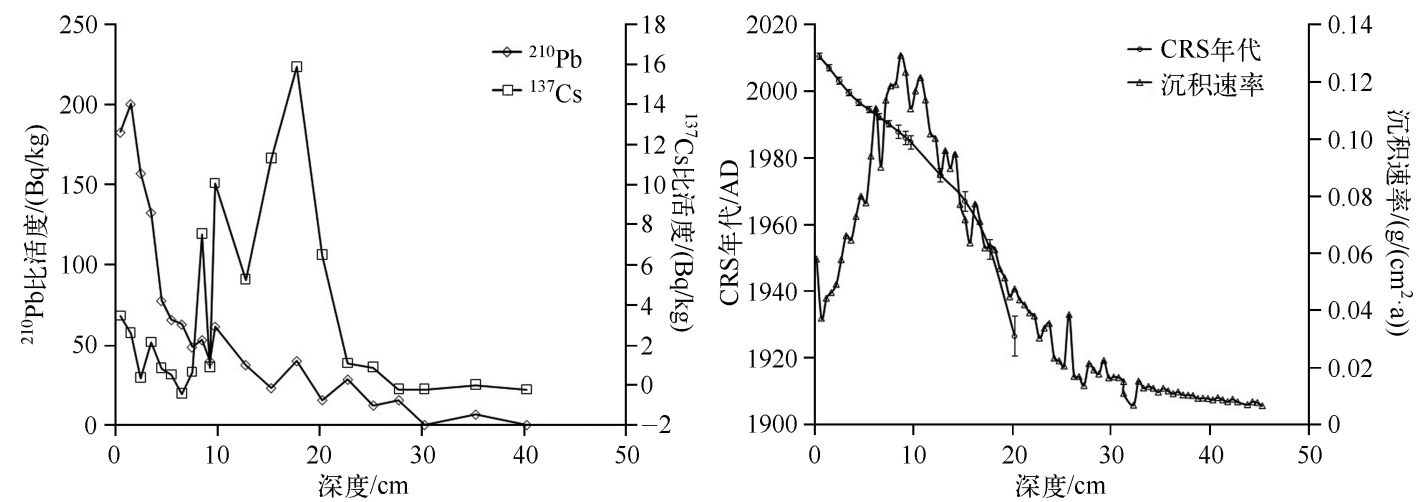

图 $2{ }^{210} \mathrm{~Pb}$ 和 ${ }^{137} \mathrm{Cs}$ 的放射性强度及沉积物年代学序列

Fig.2 CRS modeled unsupported ${ }^{210} \mathrm{~Pb}$ and ${ }^{137} \mathrm{Cs}$ profile and age versus depth 
沉积物样品中氮含量采用元素分析仪、联机 MAT 253 型同位素比质谱仪进行测定 ${ }^{[14]}$.

为探讨洱海枝角类群落变化的主要特征以及驱动因素, 本文利用 $\mathrm{R}$ 软件, rioja 程序包对枝角类群落结 构进行 CONISS 聚类分析, 通过 Broken-Stick 模型检验确认群落变化的主要阶段, 应用 vegan 程序包对枝角 类群落结构变化进行 PCA 分析, 并通过 Broken-Stick 模型检验选择显著的 PCA 主轴. 本文所采用的统计分 析在 R 软件(版本 v 2.3.0) 中完成, 沉积物地层图应用 $\mathrm{C} 2$ 软件(版本 v 1.4.3) 进行处理分析.

\section{2 结果}

\section{1 沉积物中枝角类生物量与个体大小变化的历史重建}

过去 100 年来,枝角类生物量的变化总体呈现增加的趋势, 但是存在波动变化的特征 (图 3). 从 1930s 到 1980s 枝角类生物量逐渐增加, 其中底栖枝角类生物量增加显著, 浮游枝角类的生物量增加幅度较小; 然 而, 枝角类总生物量在 1980 年达到峰值, 到 1985 年降低到低值, 其中底栖枝角类生物量大幅降低, 浮游枝角 类的生物量小幅增加.大约从 1995 年以后, 浮游枝角类生物量显著波动上升, Bosmina longispina 与 B. longirostris 都呈增加趋势, 而底栖枝角类生物量仍然处于下降的趋势. 约 2006 年以后, 浮游枝角类生物量呈大 幅下降的趋势, 底栖枝角类生物量继续呈下降趋势.

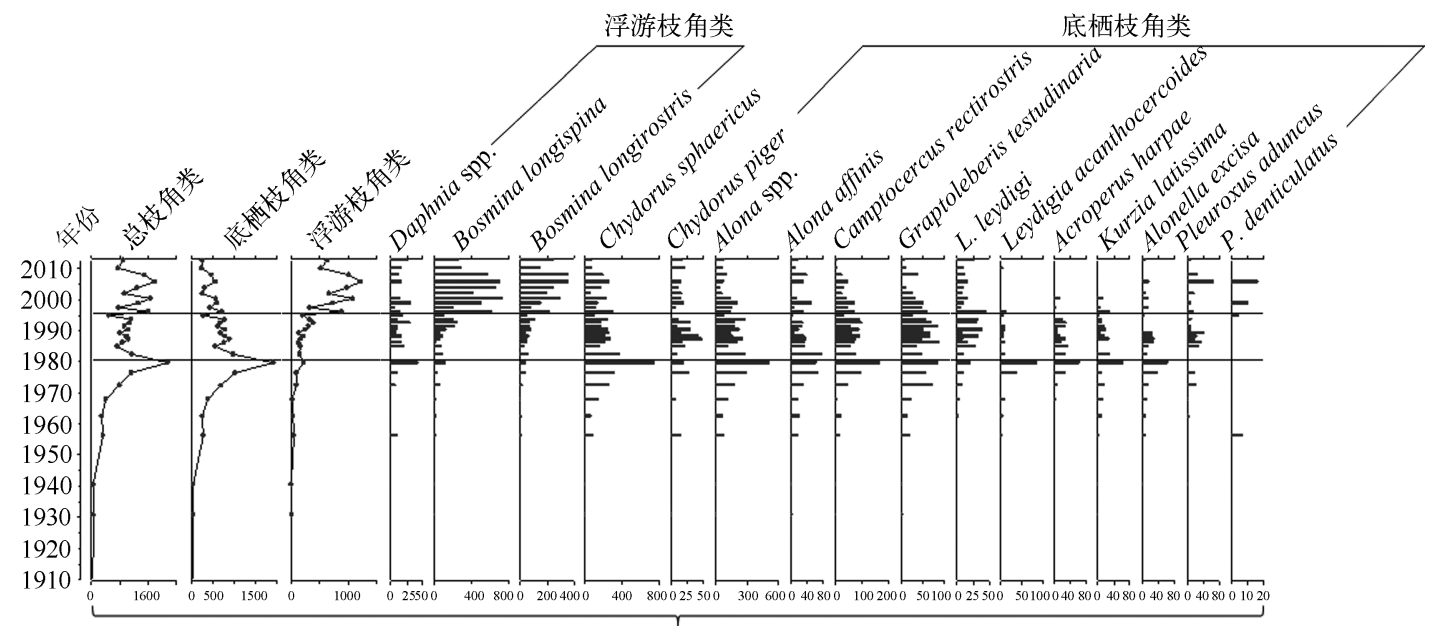

沉积通量/(ind./( $\left.\left.\mathrm{cm}^{2} \cdot \mathrm{a}\right)\right)$

图 3 洱海沉积物中枝角类生物量变化地层图

Fig.3 Stratigraphic plot showing sedimentary cladoceran changes at Lake Erhai

通过测量象鼻溞的个体大小, 发现象鼻溞生物量以及 B. longispina 第一触角长度、壳长在 1990s 初期显 著减小与此时期太湖新银鱼在洱海引种成功这一事件相一致, 可能指示了外来鱼类加剧了对湖泊中浮游动 物的捕食压力, 从而对象鼻溞种群及其个体大小产生抑制作用 (图 4). 其中, 指示象鼻溞总体大小的壳长与 较大个体物种 B. longispina 第一触角长度变化的相关性为 $0.286(n=14, P=0.322)$, 而与较小个体物种 B. longirostris 第一触角长度变化的相关性为 $-0.400(n=15, P=0.140)$. 沉积物中的枝角类群落结构在 1990 年以前以底栖枝角类为主, 象鼻溞生物量较低. 从 1990 年以后, 底栖枝角类在枝角类群落结构中所占比例逐 渐减小, 而象鼻溞比例迅速增加, 并成为枝角类群落结构中的主要组成部分, 其中 B. longispina (喜好贫营养 生境) 的比例在近年来逐渐下降,而 B. longirostris (喜好富营养生境) 的比例则逐年上升 (图 5).

\section{2 枝角类群落结构变化的特征}

枝角类群落结构变化的限制性聚类分析表明, 群落结构的变化主要有 3 个阶段, 1990 年以前整个枝角 类群落结构以底栖枝角类为主导, 浮游枝角类仅占到枝角类比例的 $23 \%$ 左右; $1990-2000$ 年枝角类的群落 结构发生急剧变化, 浮游枝角类在枝角类中所占的比例快速升高, 尤其是象鼻溞的增加, 而底栖枝角类在枝 角类中的比例呈现快速下降的趋势; 从 2000 年以后, 枝角类的群落结构基本稳定, 浮游枝角类在枝角类群 


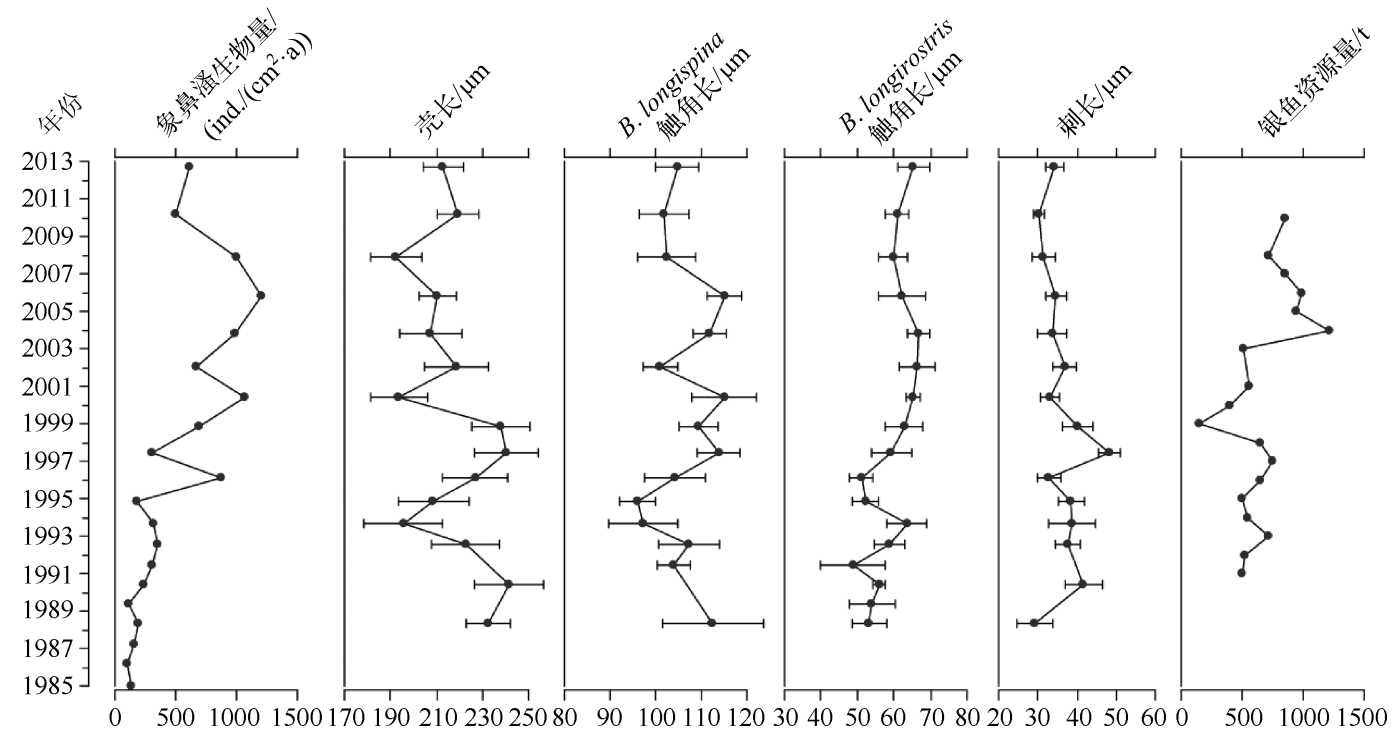

图 4 象鼻溞总生物量、个体大小变化地层图与银鱼捕捞量历史记录对比

Fig.4 Stratigraphic plot showing changes of bosminid production, body sizes and catch data of noodlefish 落结构中的比例达到 70\%左右,而底栖枝角类在枝角类群落结构中仅占到极小比例 (图 5).

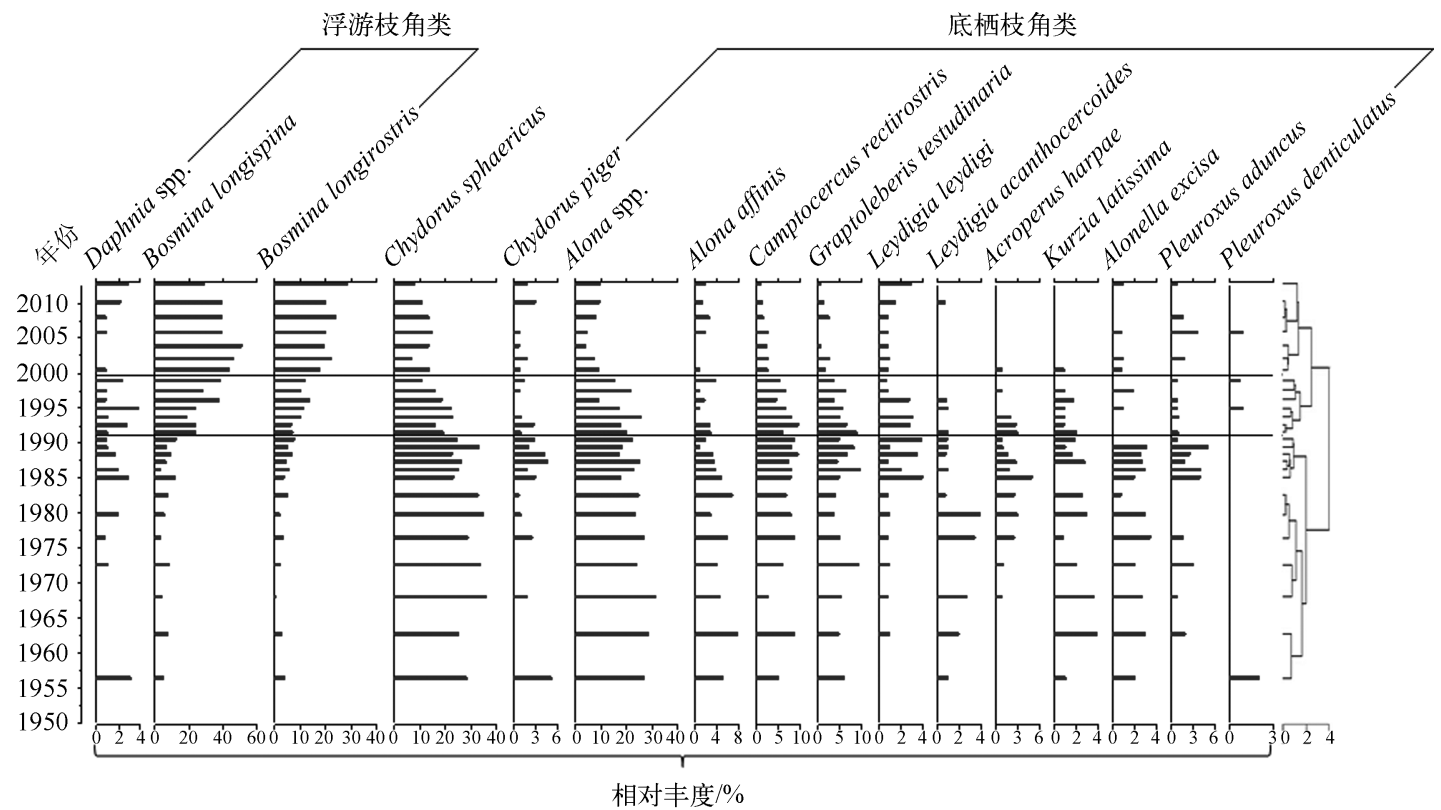

图 5 枝角类群落结构变化与限制性聚类分析

Fig.5 Profile of cladoceran community changes with constrained cluster analysis revealing three significant stages

在枝角类群落结构 PCA 分析结果基础上,运用 Broken-Stick 模型对 PCA 主轴的显著性进行检验发现, 能显著解释湖区枝角类群落结构变化的仅有 PCA 主轴 1, 共解释了群落变化方差的 $61.64 \%$. 沿 PCA 轴 1 负 方向变化的枝角类为浮游的 B. longispina 与 B. longirostris, 而沿 PCA 轴 1 正方向变化的为枝角类底栖属种, 如Alona affinis、Acroperus harpae、Graptoleberis testudinaria 等, 以及半浮游物种 Chydorus sphaericus( 图 6). 


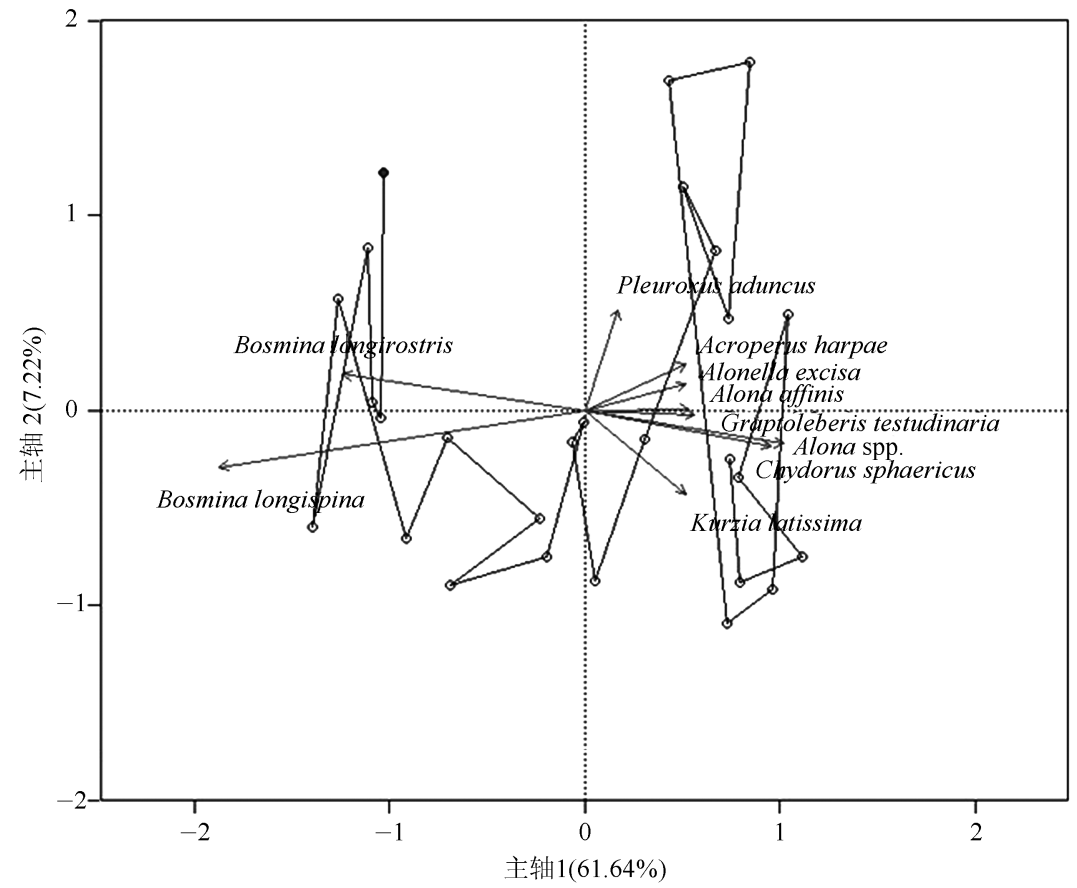

图 6 枝角类群落结构变化的 PCA 分析

Fig.6 The principal component analysis biplot of cladoceran community structure

\section{3 讨论}

沉积物记录揭示了洱海近百年枝角类群落的长期变化特征. 从 1930s 开始, 枝角类生物量总体持续增 加. 从 1990s 开始, 枝角类群落结构发生迅速更替, 浮游枝角类逐渐取代底栖枝角类成为主要组成部分, 同时 喜好贫营养生境的物种 B. longispina 在枝角类群落中所占比例近年来有所减小, 而喜好富营养生境的 B. longirostris 的比例则逐渐增加 ${ }^{[15]}$. 象鼻溞在这一时期个体大小总体减小, 与太湖新银鱼在洱海引种成功 的时间一致.1980 年以后, 枝角类群落结构出现底栖物种丰度持续偏低, 对应了此阶段洱海水生植物覆盖度 的大幅度降低 ${ }^{[2]}$.

\section{1 枝角类生物量变化特征及驱动因素}

洱海沉积物氮含量的变化 (图 7) 反映了洱海缓慢的富营养化过程, 枝角类生物量总体增加的趋势与这 一过程相对应 ${ }^{[5]}$, 但是存在较大波动, 可能反映了不同时期人类活动类型与强度的变化. 例如, 1970s 枝角类 生物量的急剧增加与西洱河水电站的修建使得洱海水位下降这一事件相一致. 湖泊水位的下降促进水草空 间分布的变化, 南部湖底平坦的湖区水深相对较浅, 水草生长茂盛, 有利于底栖枝角类生境的增加 ${ }^{[2]}$. 然而, 1980s 以后枝角类生物量的显著降低, 与吴庆龙等调查发现的洱海水生高等植被在 1980s 以后的衰退相一 致 ${ }^{[2]}$. 特别是洱海网箱养鱼的大力开展, 对水草资源的破坏性开发 ${ }^{[16]}$, 使得底栖枝角类赖以生存的环境遭到 破坏, 对枝角类生物量产生抑制作用. 从 1990s 以后, 底栖枝角类逐渐衰退, 浮游的象鼻溞成为枝角类的重要 组成部分. 而 $\mathrm{Liu}$ 等对洱海中部沉积物中的枝角类群落的研究并没有发现枝角类生物量在 $1970 \mathrm{~s}$ 急剧增加与 1980s 急剧降低的事件 ${ }^{[6]}$, 可能反映了浅水区生物群落对湖泊水位下降的响应比深水区更为敏感, 指示了生 物群落在湖泊不同水深出现的差异性响应现象. 本文的研究结果与 Liu 等识别的 1990s 以后枝角类生物量的 增加, 特别是象鼻溞相对丰度的急剧增加是一致的 ${ }^{[6]}$. 然而, Chydorus sphaericus 在 Liu 的研究中作为湖泊富 营养化的指示物种, 在 1990s 以后生物量显著增加 ${ }^{[6]}$, 这与我们的研究结果是不同的. Duigan 在对 Chydorus sphaericus 的研究中发现, 该种不仅出现在贫营养的水体中, 也经常在湖泊与池塘沿岸区的大型植被床中被 
发现, 还在蓝绿藻水华出现的地点以及高水位水体的沉水植被中被发现 ${ }^{[17]}$. 这说明 Chydorus sphaericus 生活 的生境广泛,其在洱海南部的变化特征与水生植被的退化趋势相一致, 同时也可能受到水体营养水平、水位 变化的协同影响.

洱海从 1984 年开始移植太湖新银鱼, 到 1990s 初形成稳定产量, 成为洱海渔业生产中的重要组成部分. 太湖新银鱼引人后, 现代调查显示洱海浮游动物中的枝角类、桡足类和轮虫的数量呈下降趋势, 总生物量锐 减 ${ }^{[2]}$. 我们的沉积物记录也反映出枝角类群落响应太湖新银鱼引人这一事件. 特别是象鼻溞在 $1990 \mathrm{~s}$ 初期生 物量、个体大小 (壳长以及 B. longispina 第一触角长度) 的显著减小, 与太湖新银鱼在洱海引种成功的时间相 一致. 这与我们对滇池及抚仙湖沉积物中象鼻溞的研究结果一致 ${ }^{[18]}$. Liu 等也识别了抚仙湖象鼻溞个体变小 响应太湖新银鱼的引 ${ }^{[19]}$. 然而 Liu 等研究发现 Daphnia 休眠卵长度的减小响应洱海太湖新银鱼引入这一 事实, 但是没有发现 Bosmina 个体大小有明显的变化, 本文结果表明洱海象鼻溞也响应了太湖新银鱼引人; Liu 等还识别了 1999 年 Daphnia 休眠卵长度的增加与太湖新银鱼的低产量相对应 ${ }^{[6]}$. 象鼻溞在 1999 年较大 的壳长与 B. longispina 第一触角的长度也对应了洱海这一时段太湖新银鱼的低产量. 2006 年以来, 象鼻溞生 物量及其个体大小的显著减小可能反映了湖泊中增强的鱼类捕食压力作用 (图 4). 而洱海于 2004 年开始实 行季节性休渔以及投放鱼苗等活动对浮游动物的群落结构产生了显著的调节作用 ${ }^{[20]}$.

\section{2 枝角类群落结构变化特征及驱动因素}

本文的研究结果表明洱海在近百年来经历了多重环境压力的胁迫.特别是 $1970 \mathrm{~s}$ 以来, 富营养化趋势增 强、水质恶化、水位剧烈波动、水生植被退化、鱼类群落组成变动大等, 这些因素都会对枝角类群落结构产生 重要影响 ${ }^{[1-2]}$. 现代调查数据显示洱海的水生植被在过去几十年出现了明显变化. 水生高等植物在 $1950 \mathrm{~s}-$ $1980 \mathrm{~s}$ 呈扩展趋势, 而从 1980s 开始趋于衰退, 不仅种类组成与群落类型减少, 分布面积更是大为缩减 ${ }^{[2]}$. 导 致水生植被退化的原因有多种, 无论是水体中氮、磷营养盐对水生植物的胁迫, 还是透明度、气温、水位变化 以及食物网消费者结构改变等因素都会对水生植物生长产生直接或间接的影响, 水生植被在洱海呈现长期 退化的趋势 (图 7 ${ }^{[21]}$. 而我们发现水生植被的退化所造成的底栖枝角类群落生境的丧失, 可能导致了枝角 类群落结构的改变. 从对枝角类群落 PCA 分析的结果来看, 只有第一个主轴显著且解释了枝角类群落结构 变化的 $61.64 \%$. 从沿 PCA 主轴 1 两个方向变化的物种来看, 呈现底栖枝角类逐渐被象鼻掻等浮游类型取代 的趋势. 样品点在 PCA 主轴 1 上的得分与底栖枝角类比例的变化显著相关 $(r=0.9957, n=27, P<0.001)$, 其 在 1980 年以后的急剧变化 (图 7) 与同期底栖枝角类生物量的迅速下降 (图 3) 同步, 可以看出枝角类群落结 构的长期变化主要是由底栖枝角类群落的变化导致的.水生植被覆盖面积在这一时期的显著减小 ${ }^{[22]}$, 表明 底栖枝角类赖以生存的环境的丧失. 生境的丧失导致底栖枝角类群落的生物量以及比例急剧下降. 而这一时 期指示湖泊营养水平的沉积物总氮含量增加的趋势并不明显, 浮游枝角类生物量在这一时期增加幅度也较 小, 所以不可能是增加的浮游枝角类生物量对底栖枝角类生物量的稀释作用造成的底栖枝角类比例相对减 小.从 1995 年以后, 沉积物总氮含量显著增加, 水体中总磷的监测值也同步增加 (图 7 ( $^{[6]}$, 同时浮游枝角类 的生物量大幅增加 (图 3), 可能造成了枝角类群落结构的改变. 因此, 枝角类群落结构的显著变化主要反映 了水生植被的快速变化, 而富营养化的过程也可能影响枝角类群落结构的变化.

\section{3 枝角类群落的变化与洱海生态系统的稳态转变}

在湖泊生态系统中, 清水态 (草型) 和浊水态 (藻型) 是最常见的两种稳态. 当湖泊生态系统从一种稳态 (如草型湖泊) 转变到另一种稳态 (如澡型湖泊) 时, 指示湖泊生态系统稳定性发生突变, 即稳态转变 ${ }^{[23]}$. Wang 等结合洱海的现代监测数据, 提取沉积物中记录的硅藻信息, 识别了在洱海发生稳态转变的时间为 2001 年左右并分析了湖泊生态系统转变的预警信号 ${ }^{[24]}$. 本文的枝角类群落结构分析发现, 从 2000 年左右以 后枝角类群落结构稳定, 浮游枝角类成为枝角类群落结构的主要组成部分, 这一结果与洱海发生稳态转变 的时间基本一致. 同时,枝角类群落在 1990-2000 年期间出现的显著变化也可能作为指示湖泊稳态转变预 警信号的重要指标. 同时也可能由于不同湖区在水深等方面存在的空间差异性,从而出现浅水湖区比深水区 更早出现稳态转变的时间差异性; 因此, 进一步开展不同湖区的对比研究将有助于揭示生态系统稳态转变 的时空异质性是否存在. 


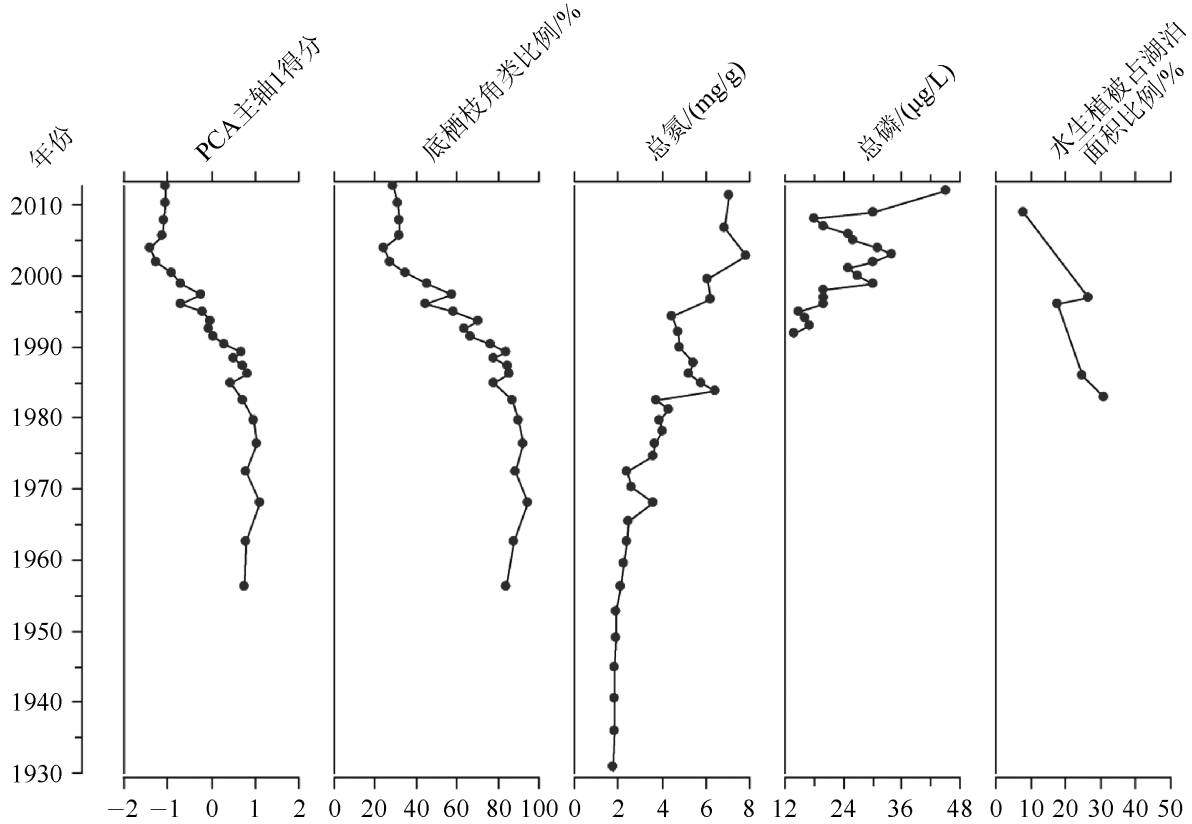

图 7 PCA 主轴 1 样品点得分、底栖枝角类比例、沉积物总氮含量、 水体总磷的现代监测数据以及水生植被覆盖面积变化

Fig.7 Stratigraphic plot showing changes of cladoceran PCA axis1 scores, relative abundance of littoral cladocerans, the sedimentary total nitrogen, the monitoring TP data, and macrophyte coverage

\section{4 结论}

本文通过对洱海沉积物多指标记录的对比研究, 在重建近百年来湖泊枝角类群落长期变化历史的基础 上, 识别了水生植被退化对枝角类群落结构转变可能起到主要的驱动作用, 同时外来鱼类引人与富营养化 过程也对枝角类群落产生重要影响.结合已有研究, 本文对比并识别了洱海不同区域的枝角类群落响应环境 压力存在一定的空间差异性, 同时枝角类群落作为指示生态系统健康的重要指标也反映了与硅藻群落指示 的洱海生态系统稳态转变的时相基本一致的特征. 总之, 本文的结果表明沉积物记录的枝角类群落信息, 可 以为了解湖泊生态系统的变化提供长期数据与一定的科学依据, 同时为洱海的有效管理与生态修复提供基 础资料.

致谢: 对在本研究中给予野外采样、室内分析等帮助的云南师范大学高原湖泊生态与全球变化重点实验室 各位老师和同学表示感谢.

\section{5 参考文献}

[ 1 ] 王云飞, 潘红秃, 吴庆龙等. 人类活动对洱海的影响及对策分析. 湖泊科学, 1999, 11(2): 123-128. DOI 10. 18307/1999. 0206.

[ 2 ] 吴庆龙, 王云飞. 洱海生物群落的历史演变分析. 湖泊科学, 1999, 11(3) : 267-272. DOI 10. 18307/1999. 0312.

[ 3 ] Smol JP. Pollution of lakes and rivers: a paleoenvironmental perspective. New Jersey: John Wiley \& Sons, 2008.

[ 4 ] Korhola A, Rautio M. Cladoceran and other branchiopod crustaceans. Dordrecht: Springer Netherlands, 2001: 5-41.

[ 5 ] Smol JP. The power of the past: using sediments to track the effects of multiple stressors on lake ecosystems. Freshwater Biology, 2010, 55(s1) : 43-59.

[ 6 ] Liu G, Liu Z, Gu B et al. How important are trophic state, macrophyte and fish population effects on cladoceran community? A study in Lake Erhai. Hydrobiologia, 2014, 736: 189-204. 
～ 7 ] 王苏民, 窦鸿身. 中国湖泊志. 北京: 科学出版社, 1998: 371-374.

[8] 王小雷, 杨 浩, 丁兆运等. 云南抚仙湖近现代沉积速率变化研究. 地理学报, 2011, 66(11): 1551-1561.

[ 9 ] Frey DG. The late-glacial cladoceran fauna of a small lake. Archiv fuir Hydrobiologie, 1958, 54: 209-275.

[10] Frey DG. Cladoceran from the Eemian Interglacial of Denmark. Journal of Paleontology, 1962, 36: 1133-1154.

[11] Frey DG. Supplement to the taxonomic and phylogenetic significance of the head pores of the Chydoridae(Cladoceran). Issue Internationale Revue der gesamten Hydrobiologie und Hydrographie, 1962, 47: 603-609.

[12] Goulden CE, Frey DG. The occurrence and significance of lateral head pores in the genus Bosmina (Cladoceran). Issue Internationale Revue der gesamten Hydrobiologie und Hydrographie, 1963, 48(3) : 513-522.

[13] Sweetman JN, Finney BP. Differential responses of zooplankton populations (Bosmina longirostris) to fish predation and nutrient-loading in an introduced and a natural sockeye salmon nursery lake on Kodiak Island, Alaska, USA. Journal of Paleolimnology, 2003, 30(2): 183-193.

[14] 朱 芸, 雷国良, 林燕语等. 元素分析仪-同位素质谱测定全氮含量的方法研究. 福建师范大学: 自然科学版, 2013, 29(1): 58-62.

[15] Boucherle MM, Züllig H. Cladoceran remains as evidence of change in trophic state in three Swiss lakes. Hydrobiologia, 1983, 103: 141-146.

［16］董云仙, 谢建平, 董云生等. 洱海水生植被资源及其可持续利用途径. 生态经济, 1996，(5)：15-19.

[17] Duigan AC. The ecology and distribution of the littoral freshwater Chydoridae (Branchiopoda, Anomopoda) of Ireland, with taxonomic comments on some species. Hydrobiologia, 1992, 241: 1-70.

[18] 卢慧斌, 陈光杰, 陈小林等. 上行与下行效应对浮游动物的长期影响评价一以滇池与抚仙湖沉积物象鼻溞为 例. 湖泊科学, 2015, 27(1) : 67-75. DOI 10. 18307/2015.0109.

[19] Liu G, Liu Z, Li Y et al. Effects of fish introduction and eutrophication on the cladoceran community in Lake Fuxian, a deep oligotrophic lake in southwest China. Journal of Paleolimnology, 2009, 42(3) : 427-435.

[20] 吴秋婷, 卫志宏, 朱 江等. 一座季节性休渔湖泊——洱海轮虫的季节动态特征. 湖泊科学, 2012, 24(4) : 586592. DOI 10. 18307/2012. 0412.

[21] 吴功果, 倪乐意, 曹 特等. 洱海水生植物与浮游植物的历史变化及影响因素. 水生生物学报, 2013, 37( 5): 912-918

[22] 厉恩华, 王学雷, 蔡晓斌等. 洱海湖滨带植被特征及其影响因素分析. 湖泊科学, 2011, 23(5): 738-746. DOI 10. 18307/2011. 0511 .

[23] Scheffer M, Hosper SH, Meijer ML et al. Alternative equilibria in shallow lakes. Trends in Ecology and Evolution, 1993, 8( 8) : 275-279.

[24] Wang R, John AD, Peter GL et al. Flickering gives early warning signals of a critical transition to a eutrophic lake state. Nature, 2012, 492: 419-422. 